\title{
Pediatric donor cell leukemia after allogeneic hematopoietic stem cell transplantation in AML patient from related donor
}

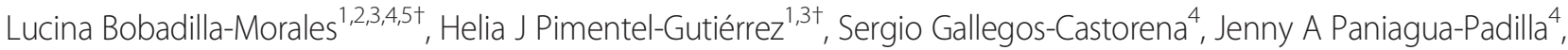 \\ Citlalli Ortega-de-la-Torre ${ }^{1,3,5}$, Fernando Sánchez-Zubieta ${ }^{1,2,3,4}$, Rocio Silva-Cruz ${ }^{1,5}$, Jorge R Corona-Rivera ${ }^{1,5}$, \\ Abraham Zepeda-Moreno ${ }^{2}$, Oscar González-Ramella ${ }^{2,4}$ and Alfredo Corona-Rivera ${ }^{1,2,3,4,5,6^{*}+}$
}

\begin{abstract}
Here we present a male patient with acute myeloid leukemia (AML) initially diagnosed as M5 and with karyotype 46,XY. After induction therapy, he underwent a HLA-matched allogeneic hematopoietic stem cell transplantation, and six years later he relapsed as AML M1 with an abnormal karyotype //47,XX,+10[2]/47,XX,+11[3]/48,XX,+10,+11 $[2] / 46, X X[13]$. Based on this, we tested the possibility of donor cell origin by FISH and molecular STR analysis. We found no evidence of $Y$ chromosome presence by FISH and STR analysis consistent with the success of the allogeneic hematopoietic stem cell transplantation from the female donor. FISH studies confirmed trisomies and no evidence of MLL translocation either p53 or ATM deletion. Additionally 28 fusion common leukemia transcripts were evaluated by multiplex reverse transcriptase-polymerase chain reaction assay and were not rearranged. STR analysis showed a complete donor chimerism. Thus, donor cell leukemia (DCL) was concluded, being essential the use of cytological and molecular approaches. Pediatric DCL is uncommon, our patient seems to be the sixth case and additionally it presented a late donor cell leukemia appearance. Different extrinsic and intrinsic mechanisms have been considered to explain this uncommon finding as well as the implications to the patient.
\end{abstract}

Keywords: Allogeneic hematopoietic stem cell transplantation, Acute myeloid leukemia, Donor cell leukemia

\section{Background}

Acute myeloid leukemia (AML) is a clinically and genetically heterogeneous hematological disease. Patient age, cytogenetic and minimal residual disease after induction therapy, play a major role in the classification and prognosis of AML, leading to stratification in risk categories [1,2].

Allogeneic hematopoietic stem cell transplantation (alloHSCT), results in superior disease-free survival and overall survival (OS) rates in patients with intermediate and high risk AML. Nowadays, many progresses have

\footnotetext{
* Correspondence: alcoronar@gmail.com

${ }^{\dagger}$ Equal contributors

${ }^{1}$ Laboratorio de Citogenética, Genotoxicidad y Biomonitoreo, Instituto de Genética Humana "Dr. Enrique Corona Rivera"/Doctorado de Biología

Molecular, Departamento de Biología Molecular y Genómica, Universidad de Guadalajara, Guadalajara, Jalisco, México

${ }^{2}$ Instituto de Investigación en Cáncer de la Infancia y la Adolescencia, Centro Universitario de Ciencias de la Salud, Universidad de Guadalajara,

Guadalajara, Jalisco, México

Full list of author information is available at the end of the article
}

been made concerning donor selection, reduction of myeloablative conditioning and management of the immunologic graft-versus-leukemia effect that all together provides a therapeutic effectiveness. Nevertheless all these advances, leukemia relapse remains the main problem that reduces the cure rates after alloHSCT [3]. A relapse is diagnosed when patient-derived cells survived the myeloablative therapy and the original leukemic cell reappears at any site in the body. Most of them occur during the first year of treatment, late relapse is not common and occurs after two years of treatment. Secondary leukemia may develop after successful treatment when non-biologically related clone to original cells arise and appears as hematologic neoplasia. Secondary leukemia must be differentiated from late relapse which descend from the same original cell that originated the primary malignancy [4]. Secondary leukemia can develop in a patient-derived clone, but in some rare cases, arise from engrafted donor cells [5], and becomes a new disorder 
known as donor cell leukemia (DCL). DCL was described in 1971 by Fialkow and colleagues and through 2011, more than 80 cases have been reported in the literature [6-8]. Most of the reported secondary AML arise after an autologous transplantation, and not allogeneic transplantation [4], this might be due to the lack of graft versus leukemia effect [5]. Relapse is observed in at least 33\% of the transplanted patients with AML/myelodysplastic syndrome and Wiseman et al. [6], suggested that up to $5 \%$ of all post-transplant leukemia correspond to DCL. Different mechanisms have been proposed to explain the etiology of DCL [9], however it remains to be established if the original mechanism whether occurred in donor or receptor cells. Most of the reported cases arise from adult patients. Pediatric DCL is uncommon, our patient seems to be the sixth reported case presented with a late appearance after 68 months. The aim of the present report is to present a male boy with AML-M5 at diagnosis successfully treated with HLA-matched sibling alloHSCT who developed a second AML-M1 in cells of donor origin.

\section{Case presentation}

A 9-year-old boy was diagnosed with AML-M5 by French American British (FAB) classification in December 2005. The bone marrow aspirate showed $100 \%$ blasts and cerebrospinal fluid was positive for leukemic blasts. Cytogenetic analysis showed a normal karyotype 46,XY. Flow cytometry immunophenotype was positive to CD13, CD33, CD34, CD38, HLA-DR, MPO, CD14, and CD11. The treatment consisted of two cycles of cytarabine $1000 \mathrm{mg} / \mathrm{m} 2$ three weeks apart. Minimal residual disease was positive at day 14 and two more induction cycles were given to achieve complete remission. He received consolidation chemotherapy and was successfully treated with alloHSCT transplantation from his HLA-identical sister. Conditioning regimen consisted on busulfan 16 doses of $1 \mathrm{mg} / \mathrm{kg} / \mathrm{PO}$ every 6 hours and cyclophosphamide $120 \mathrm{mg} / \mathrm{kg}$. Sixty-eight months after transplant the patient presented febrile with neutropenia and thrombocytopenia, bone marrow aspirates showed $98 \%$ of blasts consistent with AML M1 (Figure 1a-b), which was compatible with the immunophenotype.
The patient died after two induction cycles with the National Myeloid Protocol which consist of 7 doses of cytarabine $100 \mathrm{mg} / \mathrm{m} 2$, 3 doses of daunorrubicin $50 \mathrm{mg} / \mathrm{m} 2$ and five days with central nervous system prophylaxis with intrathecal chemotherapy (methotrexate/cytarabine/hydrocortisone). Minimal residual disease before the second cycle was $8 \%$ and the patient died by septic shock 7 days after he finished the second cycle.

The bone marrow morphology of M5 at diagnosis was confirmed with immunophenotype, CD13, CD33, CD34, CD38, HLA-DR, MPO, CD14, and CD11. At relapse, the morphology and immunophenotype positive for HLADR, CD117, MPO, CD38, CD34, CD45, CD15 (mild) and CD13, concluded AML M1. Additional studies were performed on relapse as follows.

\section{Discussion and conclusions}

Here we present a case of a DCL AML-M1 formerly diagnosed as AML-M5 in a pediatric male patient successfully treated with a HLA-matched alloHSCT. The karyotype, FISH and STR analysis evidenced a completely new disease on female donor cells, indicating a successful transplant and implying a different and more complex approach of the case.

DCL is a rare but well-recognized disease that affects patients treated with hematopoietic cells transplantation as a late complication [6]. This patients develop a secondary leukemia from cells derived from the donor and the diagnosis depends on the ability to accurately identify the donor origin of the leukemic cells [8]. In these case we conclude that our patient acquired a secondary leukemia derived from his sister donor cells since FISH analysis showed $100 \%$ of XX centromeres of the analyzed leukocytes. Molecular testing by STR analysis demonstrated that sample from bone marrow and mucosal swap from the patient had different DNA.

Abnormal cytogenetics has been found in $72 \%$ of cases with DCL/myelodisplastic neoplasms, being the most common aberrations chromosome 7 monosomy or $7 \mathrm{q}$ deletion (29\%), occurring always in myeloid neoplasms (AML or myelodysplastic syndrome (MDS) so far there is no evidence of a structural or numerical aberration

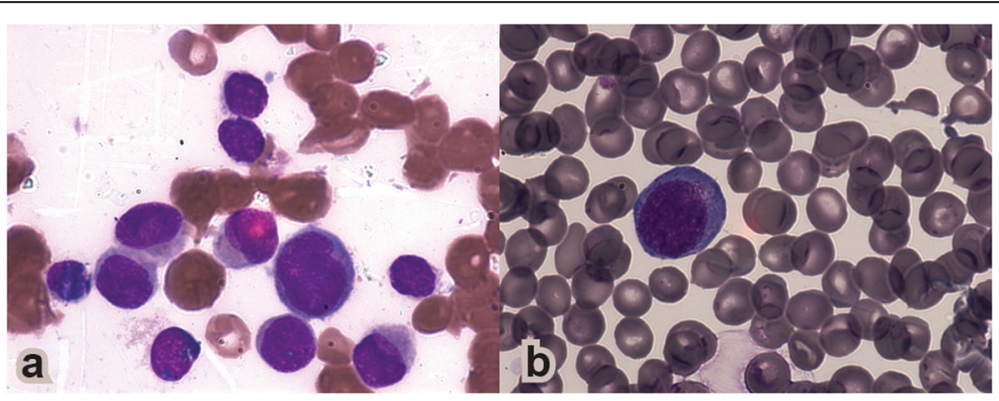

Figure 1 Bone marrow aspirates. a) At diagnosis as LMA M5. b) At relapse as LMA M1. 
patterns in DCL $[7,10]$. The karyotype may be the initial approach to search for DCL [6], as occurred in our patient. Isolated trisomy 10 is an extremely uncommon event, in pediatric leukemia. In a review, Yuan et al., reported just 3 pediatric and 20 adults AML patients with trisomy 10 and their impact in disease progression and prognosis remains unclear [11]. Despite the few cases with +10 , the most have been observed in AML M1 patients [12]. Trisomy 11 is a rare event associated with poor prognosis, Alseraye et al. [1], reported a group of 18 patients with trisomy 11 that included de novo AML cases, patients with a history of MDS and patients with a progressive clinical course of refractory or relapsed disease. Suzuki et al. [12], found a low incidence of trisomy 10 $(0.28 \%)$ and trisomy $11(0.47 \%)$ as a sole abnormality from 1074 adult AML patients. Morphology of $55 \%$ of the patients was classified as AML-M1 and the OS was 5 months. We did not find a case report with both 10 and 11 trisomies in the same patient, in concordance with Alseraye et al. [1], our patient classified as AML-M1 and trisomy 11 , also presented an unfortunate ending since he died before acquire remission after 2 months of diagnosis from the DCL. The initial and post-transplant karyotypes suggest that the original leukemic cell population was different from the new one. Furthermore, TEL-AML1 fusion gene, which has been implicated in late relapses [13], was not translocated in our patient [13]. Our case did not have structural abnormalities and observed numerical aberrations seem to be associated to the observed leukemia, at present no prognosis abnormality has been defined.

Previous reports have shown that alkylating agents, and topoisomerasa II inhibitors are a risk factor to develop secondary AML [14]. Patients treated with topoisomerasa-II inhibitors typically results with MLL (11q23) [15], or less common RUNX1 gene (21q22) translocations. Alkylating agents presents in $90 \%$ of the cases loss of part or complete chromosomes 5 and/or 7 $[14,16]$. Our patient was treated with doxorubicin a topoisomerasa-II inhibitor and cyclophosphamide, a well known alkylating agent [14] and due to the treatment received, the patient was in the higher risk to develop a secondary leukemia however, we did not find any rearrangement in MLL gene or deletion in chromosome 5 and 7. Then, we may no support in our patient chemotherapy related DCL.

Wiseman [6], reported that 75\% of DCL are different from the original disease and that arise as AML in 53\% of cases $25 \%$ as ALL and 20\% as MDS. Our patient was formerly diagnosed with AML-M5 and as with AMLM1 in the second leukemia, maintaining the same lineage but in a different maturation stage. We found in the literature, 5 pediatrics cases of DCL. In 3/5, they relapsed with different lineage and in contrast with the adult DCL which most of them originates in an AML or MDS, in the pediatric patients $50 \%$ of the DCL are ALL and $50 \%$ AML. In previous reports of pediatrics patients, the maximum period of time after transplant and DCL was 23 months, in our case the patient relapsed after 68 months. The pediatric DCL cases are presented in Table 1.

Different mechanisms have been proposed to explain the etiology of DCL. Extrinsic factors focus on chemotherapy and radiation-induced stromal abnormalities $[6,8,21]$. Intrinsic factors may be related to the donor, such as leukemia previously present in donor cells or leukemic predisposition [6]. On the other hand intrinsic factors can be related to the recipient, including impaired immune function [8], transformation of donor cells by antigenic stimulation through host tissue, oncogene transfection from abnormal to normal cells [9], replication stress, and host microenvironment $[7,22]$. Not all cases that develop DCL arise from previous malignant diseases [9], suggesting alternative explanations to stromal abnormalities and oncogene transfection theories $[9,10]$. Any specific conditioning, graft manipulation and graft-versus-host disease prophylaxis has been identified as risk factors for DCL [23].

Additionally to numerical chromosomal abnormalities, we were not able to detect structural cytogenetic and molecular abnormalities in donor cells. Related to this, the donor sister has been maintained without clinical evidence of hematologic disorder, and apparently healthy. Besides, the observation of normal tested tumor suppressor genes, fusion genes absence, and MLL integrity, support that more host microenvironment conditions that donor cells may be implicated. Despite the microenvironmental

Table 1 Reported pediatric cases of donor cell leukemia and present case

\begin{tabular}{|c|c|c|c|c|c|c|}
\hline Age & 1st disease & 2nd disease & Months after transplant & Source & Donor & Author \\
\hline 4 & AML & $\mathrm{AML}$ & 23 & $\mathrm{BM}$ & Brother & {$[17]$} \\
\hline 12 & $\mathrm{CML}$ & ALL & 15 & BM & Sister & [18] \\
\hline$N A^{*}$ & T-ALL & B-ALL & NA & BMT & NA & [19] \\
\hline 16 & AML & B-ALL & 12 & BMT & Brother & [20] \\
\hline 3 & AML M5 & AML & 14.5 & UCB & Unrelated & [7] \\
\hline 16 & AML M5 & AML M1 & 68 & BMT & Sister & Present case \\
\hline
\end{tabular}




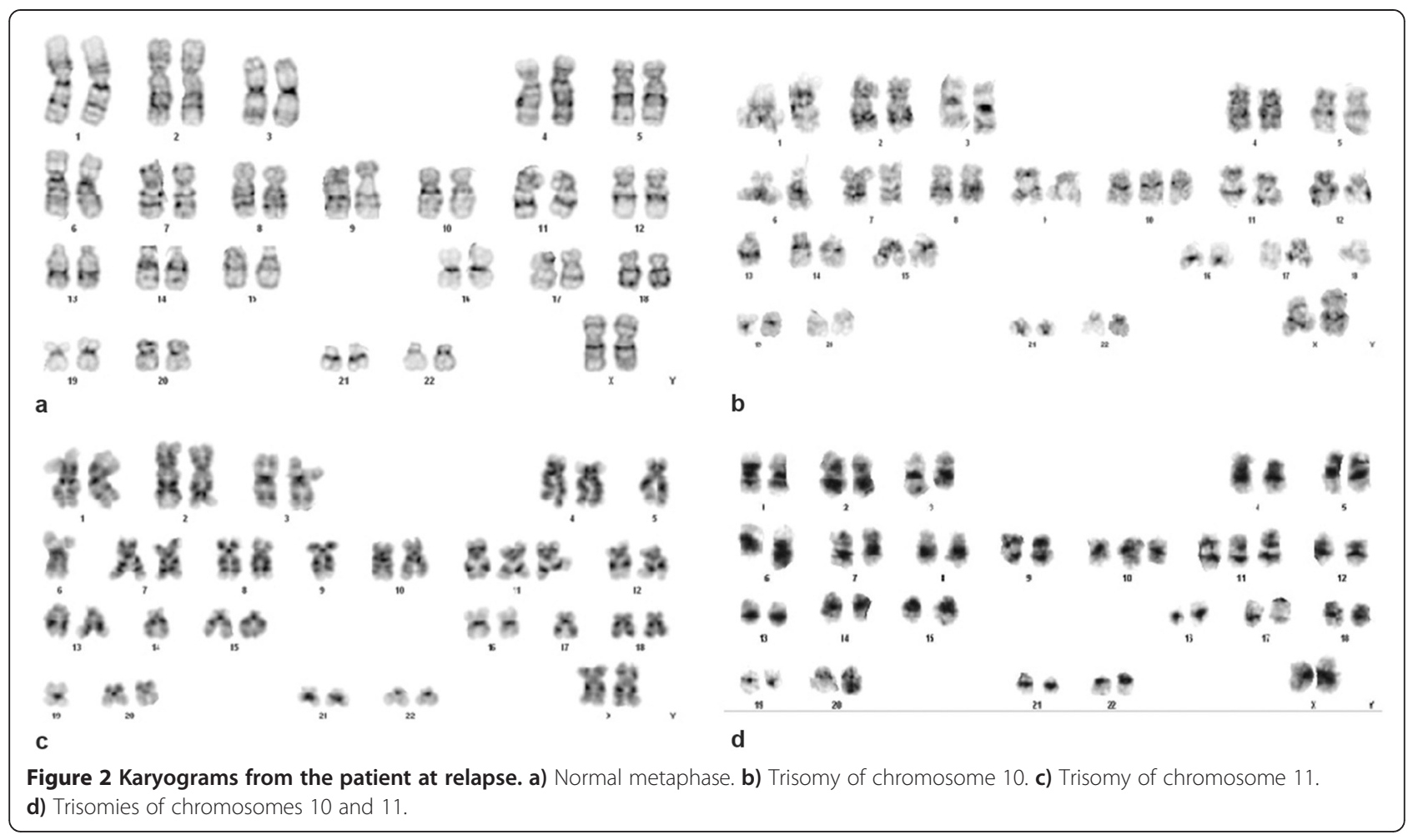

theory, more information about the disease biology is needed to confirm if the original mechanism occurred in donor or receptor cells $[9,21,24]$. A multifactorial component may be involved, and considering that from $5 / 6$ pediatric DCL the donor has been related, there could be a familial predisposing involvement.
In summary, pediatric DCL might be a less heterogeneous group that those observed in adults. To identify the presence of DCL is essential the use of cytological and molecular approaches which eliminate the possibility of a relapse from the original clone. Nevertheless the DCL in our patient has been well supported, the direct
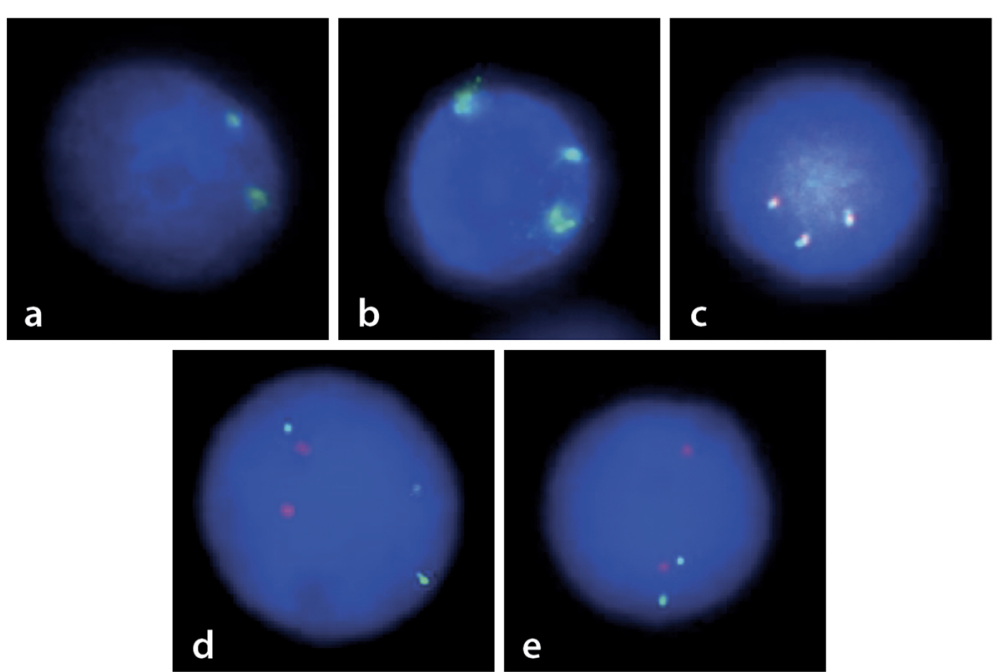

Figure 3 Interphase FISH studies. a) XY probe (X spectrum green and $Y$ spectrum red) shows the presence of donor female cells. b) CEP 10 (spectrum green) probe supports the trisomy of chromosome 10. c) No disruption of MLL gene was observed using a MLL break apart probe; the third signal corresponds to the extra chromosome 11. d) Simultaneous p53 (spectrum green) and ATM (spectrum Orange) test, showed no deletion of any suppressor gene, but the third signal of ATM agrees with the trisomy 11. e) Tel-AML1 (red/green signal) evaluation was negative for the presence of the fusion gene. 
Table 2 Post-transplant STR analysis from the patient mucosal swap, bone marrow, and blood from the donor

\begin{tabular}{|c|c|c|c|c|c|c|}
\hline \multirow{2}{*}{$\frac{\text { Marker }}{\text { D8S1179 }}$} & \multicolumn{2}{|c|}{ Patient's mucosal swap at relapse } & \multicolumn{2}{|c|}{ Patient's bone marrow at relapse } & \multicolumn{2}{|c|}{ Donor's blood } \\
\hline & 10 & 10 & 10 & 10 & 10 & 10 \\
\hline D21S11 & 28 & 30 & 28 & 30 & 28 & 30 \\
\hline D75820 & 10 & 12 & 10 & 12 & 10 & 12 \\
\hline CSF1PO* & 9 & 12 & 9 & 10 & 9 & 10 \\
\hline D3S1358* & 15 & 17 & 17 & 17 & 17 & 17 \\
\hline TH01* & 7 & 7 & 8 & 8 & 8 & 8 \\
\hline D13S317* & 10 & 13 & 10 & 12 & 10 & 12 \\
\hline D16S539* & 10 & 12 & 10 & 10 & 10 & 10 \\
\hline D19S433 & 14.2 & 15 & 14.2 & 15 & 14.2 & 15 \\
\hline vWA* & 16 & 16 & 16 & 18 & 16 & 18 \\
\hline TPOX* & 8 & 12 & 11 & 11 & 11 & 11 \\
\hline D18S51 & 17 & 18 & 17 & 18 & 17 & 18 \\
\hline DS5818* & 7 & 12 & 12 & 12 & 12 & 12 \\
\hline $\mathrm{FGA}^{*}$ & 24 & 25 & 25 & 26 & 25 & 26 \\
\hline Amelogenina & $x$ & Y & $x$ & $x$ & $x$ & $x$ \\
\hline
\end{tabular}

* $=$ informative alleles.

Table 3 Involved translocation genes studied by nested multiplex PCR

\begin{tabular}{|c|c|c|c|c|c|}
\hline Traslocation* & Genes & Traslocation & Genes & Traslocation & Genes \\
\hline \multirow[t]{2}{*}{$t(X ; 11)(q 13 ; q 23)$} & MLL (11q23) & TAL1 (deleción) & STIL (1p32) & $\mathrm{t}(9 ; 22)(\mathrm{q} 34 ; \mathrm{q} 11)$ & $\mathrm{BCR}(22 \mathrm{q} 11)$ \\
\hline & FOZO4 (Xq13.1) & & TAL1 (1p32) & & ABL1 (9q34.1) \\
\hline \multirow[t]{2}{*}{$\mathrm{t}(6 ; 11)(\mathrm{q} 27 ; \mathrm{q} 23)$} & MLL (11q23) & $\mathrm{t}(8 ; 21)(\mathrm{q} 22 ; \mathrm{q} 22)$ & RUNX1 (21q22.3) & $\mathrm{t}(9 ; 12)(\mathrm{q} 34 ; \mathrm{p} 13)$ & ETV6 (12p13) \\
\hline & MLLT4 (6q27) & & RUNX1T1 (8q22) & & ABL1 (9q34.1) \\
\hline \multirow[t]{2}{*}{$\mathrm{t}(11 ; 19)(q 23 ; p 13.1)$} & MLL (11q23) & $\mathrm{t}(3 ; 21)(\mathrm{q} 26 ; \mathrm{q} 22)$ & RUNX1 (21q22.3) & $\mathrm{t}(5 ; 12)(q 33 ; p 13)$ & ETV6 (12p13) \\
\hline & ELL (19p13.1) & & MDS1 (3q26) & & PDGFRB (5q33) \\
\hline \multirow[t]{2}{*}{$\mathrm{t}(10 ; 11)(p 12 ; q 23)$} & MLL (11q23) & $\mathrm{t}(16 ; 21)(\mathrm{p} 11 ; \mathrm{q} 22)$ & FUS (16p11.2) & $\mathrm{t}(12 ; 22)(p 13 ; q 11-12)$ & ETV6 (12p13) \\
\hline & MLLT10(10P12) & & ERG (21q22.3) & & MN1 (22q12.1) \\
\hline \multirow[t]{2}{*}{$\mathrm{t}(1 ; 11)(\mathrm{p} 32 ; \mathrm{q} 23)$} & MLL (11q23) & $\mathrm{t}(15 ; 17)(\mathrm{q} 22 ; \mathrm{q} 12)$ & PML (15q22) & $t(6 ; 9)(p 23 ; q 34)$ & DEK (6p23) \\
\hline & EPS15 (1p32) & & RARA (17q12) & & NUP214 (9q34) \\
\hline \multirow[t]{2}{*}{$\mathrm{t}(11 ; 17)(q 23 ; q 12-21)$} & MLL (11q23) & $\mathrm{t}(9 ; 22)(\mathrm{q} 34 ; \mathrm{q} 11)$ & $\mathrm{BCR}(22 \mathrm{q} 11)$ & $\mathrm{t}(9 ; 9)(\mathrm{q} 34 ; \mathrm{q} 34)$ & SET (9q34) \\
\hline & MLLT6 (17q21) & & ABL1 (9q34.1) & & NUP214 (9q34) \\
\hline \multirow[t]{2}{*}{$\mathrm{t}(11 ; 19)(q 23 ; p 13.3)$} & MLL (11q23) & $\mathrm{t}(4 ; 11)(\mathrm{q} 21 ; \mathrm{q} 23)$ & MLL (11q23) & $\operatorname{inv}(16)(p 13 ; q 22)$ & CBFB (16q22.1) \\
\hline & MLLT1 (19P13.3) & & AFF1 (4q21.3) & & MYH11 (16p13.11 \\
\hline \multirow[t]{2}{*}{$t(10 ; 11)(p 12 ; q 23)$} & MLL (11q23) & $\mathrm{t}(10 ; 11)(\mathrm{p} 12 ; \mathrm{q} 23)$ & MLL (11q23) & $\mathrm{t}(3 ; 21)(\mathrm{q} 26 ; \mathrm{q} 22)$ & RUNX1 (21q22.3) \\
\hline & MLLT10 (10p12) & & MLLT10 (10p12) & & EAP (3q26) \\
\hline \multirow[t]{2}{*}{$\mathrm{t}(9 ; 11)(\mathrm{p} 22 ; \mathrm{q} 23)$} & MLL (11q23) & $\mathrm{t}(11 ; 19)(\mathrm{q} 23 ; \mathrm{P} 13.3)$ & MLL (11q23) & $\mathrm{t}(11 ; 17)(q 23 ; q 12-21)$ & ZBTB16 (11q23) \\
\hline & MLLT3 (9p22) & & MLLT1 (19p13.3) & & RARA (17q12) \\
\hline \multirow[t]{2}{*}{$\mathrm{t}(1 ; 19)(\mathrm{q} 23 ; \mathrm{p} 13)$} & TCF3 (19p13.3) & $\mathrm{t}(9 ; 11)(\mathrm{p} 22 ; \mathrm{q} 23)$ & MLL (11q23) & $\mathrm{t}(3 ; 21)(\mathrm{q} 26 ; \mathrm{q} 22)$ & RUNX1 (21q22.3) \\
\hline & PBX1 (1q23.3) & & MLLT3 (9p22) & & EVI1 (3q26) \\
\hline \multirow[t]{2}{*}{$t(17 ; 19)(q 22 ; p 13)$} & TCF3 (19p13.3) & $\mathrm{t}(1 ; 11)(\mathrm{q} 21 ; \mathrm{q} 23)$ & MLL (11q23) & $\mathrm{t}(15 ; 17)(\mathrm{q} 22 ; \mathrm{q} 12)$ & PML (15q22) \\
\hline & HLF (17q22) & & MLLT11 (1q21) & & RARA (17q12) \\
\hline \multirow[t]{2}{*}{$t(12 ; 21)(p 13 ; q 22)$} & ETV6 (12p13) & $\operatorname{inv}(16)(p 13 ; q 22)$ & CBFB (16q22.1) & $\mathrm{t}(3 ; 5)(\mathrm{q} 25.1 ; \mathrm{q} 35)$ & NPM1 (5q22) \\
\hline & RUNX1 (21q22.3) & & MYH11 (16p13.11 & & MLF1 (3q25.1) \\
\hline
\end{tabular}

${ }^{*}=$ All the translocations tested were negative in our patient. 
mechanism involved is still elusive. We suggest that defects in the host marrow microenvironment may be frequently implicated.

\section{Material and methods Cytogenetic studies}

Cytogenetic analysis performed on bone marrow sample using standard culture methods and GTW banding showed an abnormal female karyotype: //47,XX,+10[2]/47, $\mathrm{XX},+11[3] / 48, \mathrm{XX},+10,+11[2] / 46, \mathrm{XX}[13]$ (Figure 2a-d).

\section{FISH studies}

To test for the presence of additional 10 and 11 chromosomes, we performed Fluorescence in situ hybridization (FISH), on bone marrow samples using centromere 10 (CEP 10 green, KBI-20010G, Kreatech), and MLL (LSI dual dolor break apart, 05 J90-001, Abbott Molecular) FISH probes. The results were reported according to ISCN 2013 as follows. Centromere 10: //nucish(D10Z1x3) [92/200]. MLL: //nuc ish(5'MLL con 3'MLLx3)[150/200]. Cep 10 and MLL showed three copies, agreeing with the trisomy 10 and 11 found in karyotype (Figure 2b,c).

The sex chromosomes status was tested using centromeres X/Y (SE DXZ1 green/SE DXZ1 red, KBI-20030, Kreatech) FISH probe, resulting as follows: //nucish (DXZ1x2)[192/200]. The presence of a pair of centromere $\mathrm{X}$ sequences supports a donor cell origin, (Figure $3 \mathrm{a}$ ).

Complimentary FISH probes on bone marrow samples using TEL/AML1(LSI TEL SG/LSI AML1 SO, 05 J62001, Abbott Molecular) and TP53/ATM (LSI TP53 SG/ LSI ATM SO, 05 J83-001, Abbott Molecular), resulted in normal fluorescence patterns, although ATM exhibited an additional signal showing the extra 11 chromosome (Figure 3d,e).

STR studies. Microsatellite short tandem repeat (STR) analysis were performed for 15 loci (CSF1PO, D2S1338, D3S1358, D5S818, D7S820, D8S1179, D13S317, D16S539, D18S51, D19S433, D21S11, FGA, TH01, TPOX, and vWA) and sex determination by amelogenin (AmpFLSTR Identifiler, 4322288, Life Technologies) on genomic DNA from bone marrow and mucosal swap of the posttransplant patient and in blood from the donor (Table 2). From the 15 microsatellite markers tested, differences were found between the oral mucosal and blood from the patient in the 9/14 informative alleles and Y chromosome was not detected concluding that the AML was derived from the donor cells.

\section{Multiplex PCR studies}

To detect the most common fusion transcripts found in AML and ALL, we performed nested multiplex reverse transcriptase-polymerase chain reaction assay (HemaVision, HV01-28 N, DNA Technology A/S). The 28 fusion transcripts evaluated are shown in Table 3. Our patient was negative for the amplification of all of them, while the endogenous controls were positive in every PCR reaction.

\section{Consent}

Written informed consent was obtained from the patient's parents for publication of this Case report and any accompanying images. A copy of the written consent is available for review by the Editor-in-Chief of this journal.

\begin{abstract}
Abbreviations
AML: Acute myeloblastic leukemia; alloHSCT: Hematopoietic stem cell transplant; FAB: French American British; FISH: Fluorescence in situ hybridization; GTW: $G$ bands by trypsin and Wright's stain; HLA: Human leukocyte antigen; MDS: Myelodysplastic syndrome; nucish: Nuclear in situ hybridization; OS: Overall survival; STR: Short tandem repeats; UCB: Umbilical cord blood.
\end{abstract}

\section{Competing interests}

The authors declare that they have no competing interests.

\section{Authors' contributions}

$\mathrm{BML}$, participated in the cytogenetic studies, manuscript preparation and technical review and supervision. PGHJ, performed FISH and molecular studies, and participated in the manuscript preparation. GCS, participated in the patient clinical management and case review, as well as critical literature review. PPJA, participated in the patient clinical management and case review. OTC, performed STR and FISH studies. SZF, participated in the patient clinical management and case review. SCR, performed multiplex PCR studies. CRJR, participated in the manuscript critical review. ZMA, participated in the manuscript critical review. GRO, participated in manuscript review and initial patient management. CRA, participated in the manuscript preparation, general coordination and technical review. All authors read and approved the final manuscript.

\section{Acknowledgements}

We appreciate the support provided by the staff from the Unidad de Citogenetica, NHCJIM and Laboratorio de Citogenetica Genotoxicidad y Biomonitoreo, CUCS, U. de G.

\section{Author details}

'Laboratorio de Citogenética, Genotoxicidad y Biomonitoreo, Instituto de Genética Humana "Dr. Enrique Corona Rivera"/Doctorado de Biología Molecular, Departamento de Biología Molecular y Genómica, Universidad de Guadalajara, Guadalajara, Jalisco, México. ${ }^{2}$ Instituto de Investigación en Cáncer de la Infancia y la Adolescencia, Centro Universitario de Ciencias de la Salud, Universidad de Guadalajara, Guadalajara, Jalisco, México. ${ }^{3}$ Unidad de Citogenética, Servicio de Hematología y Oncología Pediátrica, División de Pediatría, Nuevo Hospital Civil de Guadalajara, "Dr. Juan I. Menchaca", Guadalajara, Jalisco, México. ${ }^{4}$ Servicio de Hematología y Oncología Pediátrica, División de Pediatría, Nuevo Hospital Civil de Guadalajara, “Dr. Juan I. Menchaca", Guadalajara, Jalisco, México. ${ }^{5}$ División de Pediatría, Centro de Registro e Investigación sobre Anomalías Congénitas (CRIAC), Nuevo Hospital Civil de Guadalajara, "Dr. Juan I. Menchaca", Guadalajara, Jalisco, México.

'Laboratorio de Citogenética Genotoxicidad y Biomonitoreo, Instituto de Genética Humana "Dr. Enrique Corona-Rivera", Departamento de Biología Molecular y Genómica, Centro Universitario de Ciencias de la Salud, Universidad de Guadalajara, \#Sierra Mojada 950, S.L., Edificio P, Nivel 2, Col. Independencia, Guadalajara, Jalisco CP: 44340, México.

Received: 19 September 2014 Accepted: 26 December 2014 Published online: 31 January 2015

\section{References}

1. Alseraye FM, Zuo Z, Bueso-Ramos C, Wang S, Medeiros LJ, Lu G. Trisomy 11 as an isolated abnormality in acute myeloid leukemia is associated with unfavorable prognosis but not with an NPM1 or KIT mutation. Int J Clin Exp Pathol. 2011:4:371-7.

2. Pui $\mathrm{CH}$, Carroll WL, Meshinchi S, Arceci RJ. Biology, risk stratification, and therapy of pediatric acute leukemias: an update. J Clin Oncol. 2011;29:551-65.

3. Pavletic SZ, Kumar S, Mohty M, de Lima M, Foran JM, Pasquini M, et al. NCl first international workshop on the biology, prevention, and treatment of relapse 
after allogeneic hematopoietic stem cell transplantation: report from the committee on the epidemiology and natural history of relapse following allogeneic cell transplantation. Biol Blood Marrow Transplant. 2010;16:871-90.

4. Cho BS, Kim HJ, Eom KS, Lee JW, Min WS, Kim CC. A case report of the second de novo acute myeloid leukemia (AML) following allogeneic stem cell transplantation in a patient with the first AML. Korean J Intern Med. 2010;25:110-3.

5. Reichard K, Zhang QY, Sanchez L, Hozier J, Viswanatha D, Foucar K. Acute myeloid leukemia of donor origin after allogeneic bone marrow transplantation for precursor T-cell acute lymphoblastic leukemia: case report and review of the literature. Am J Hematol. 2006;81:178-85.

6. Wiseman DH. Donor cell leukemia: a review. Biol Blood Marrow Transplant. 2011;17:771-89.

7. Wang E, Hutchinson CB, Huang Q, Lu CM, Crow J, Wang FF, et al. Donor cellderived leukemias/myelodysplastic neoplasms in allogeneic hematopoietic stem cell transplant recipients: a clinicopathologic study of 10 cases and a comprehensive review of the literature. Am J Clin Pathol. 2011;135:525-40.

8. Flynn CM, Kaufman DS. Donor cell leukemia: insight into cancer stem cells and the stem cell niche. Blood. 2007;109:2688-92.

9. Fraser CJ, Hirsch BA, Dayton V, Creer MH, Neglia JP, Wagner JE, et al. First report of donor cell-derived acute leukemia as a complication of umbilical cord blood transplantation. Blood. 2005;106:4377-80.

10. Otero L, de Souza DC, de Cassia TR, Gomes BE, Padilha TF, Bouzas LF, et al. Monosomy 7 in donor cell-derived leukemia after bone marrow transplantation for severe aplastic anemia: Report of a new case and review of the literature. Genet Mol Biol. 2012;35:734-6.

11. Yuan J, McDonough C, Kulharya A, Ramalingam P, Manaloor E. Isolated trisomy 10 in an infant with acute myeloid leukemia: a case report and review of literature. Int J Clin Exp Pathol. 2010;3:718-22.

12. Suzuki A, Kimura Y, Ohyashiki K, Kitano K, Kageyama S, Kasai M, et al. Trisomy 10 in acute myeloid leukemia. Three additional cases from the database of the Japan Adult Leukemia Study Group (JALSG) AML-92 and AML-95. Cancer Genet Cytogenet. 2000;120:141-3.

13. Bhojwani D, Pei D, Sandlund JT, Jeha S, Ribeiro RC, Rubnitz JE, et al. ETV6RUNX1-positive childhood acute lymphoblastic leukemia: improved outcome with contemporary therapy. Leukemia. 2012;26:265-70.

14. Leone G, Pagano L, Ben-Yehuda D, Voso M. Therapy-related leukemia and myelodysplasia: susceptibility and incidence. Haematologica. 2007;92:1389-98.

15. Godley L, Larson R. Therapy-related myeloid leukemia. Semin Onco. 2008:35:418-29.

16. Larson R. Therapy-related myeloid neoplasms. Haematologica. 2009;94:454-9.

17. Goh K, Klemper MR. In vivo leukemic transformation: cytogenetic evidence of in vivo leukemic transformation of engrafted marrow cells. Am J Hematol. 1977;2:283-90.

18. Smith JL, Heerema NA, Provisor AJ. Leukaemic transformation of engrafted bone marrow cells. Br J Haematol. 1985;60:415-22.

19. Feig SA, Dreazen O, Simon M, Wiley F, Schreck F, Gale RP. B cell acute lymphoblastic leukemia (ALL) in donor cells following bone marrow transplantation for T cell ALL. Bone Marrow Transplant. 1988;3(4):331-7.

20. Mouratidou M, Sotiropoulous D, Deremitzaki K, Spathas DH, Hoffbrand AV, Prentice $\mathrm{HG}$, et al. Recurrence of acute leukemia in donor cells after bone marrow transplantation: documentation by in situ DNA hybridization. Bone Marrow Transplant. 1993;12:77-80

21. Sala TO, Loeb KR. Donor cell-derived leukemia and myelodysplastic neoplasm: unique forms of leukemia. Am J Clin Pathol. 2011;135:501-4.

22. Wang $H$, Chen $X Q$, Geng QR, Liu PP, Lin GN, Xia ZJ, et al. Induction therapy using the MRC UKALLXII/ECOG E2993 protocol in Chinese adults with acute lymphoblastic leukemia. Int J Hematol. 2011;94:163-8.

23. Hertenstein B, Hambach L, Bacigalupo A, Schmitz N, McCann S, Slavin S, et al. Development of leukemia in donor cells after allogeneic stem cell transplantation-a survey of the European Group for Blood and Marrow Transplantation. Haematologica. 2005;90:969-75.

24. Kim YW, Koo BK, Jeong HW, Yoon MJ, Song R, Shin J, et al. Defective Notch activation in microenvironment leads to myeloproliferative disease. Blood. 2008:112:4628-38.

\section{Submit your next manuscript to BioMed Central and take full advantage of:}

- Convenient online submission

- Thorough peer review

- No space constraints or color figure charges

- Immediate publication on acceptance

- Inclusion in PubMed, CAS, Scopus and Google Scholar

- Research which is freely available for redistribution 